\title{
Bovine Rotavirus V1005 a P5, Not a P12, Type like All Viruses in a German Survey
}

\author{
HARALD BRÜSSOW, ${ }^{1 *}$ ANGELA ROHWEDDER, ${ }^{2}$ OSAMU NAKAGOMI, ${ }^{3}$ \\ JOSETTE SIDOTI, ${ }^{1}$ AND WERNER EICHHORN ${ }^{4}$ \\ Nestlé Research Centre, Nestec Ltd., Vers-chez-les-Blanc, CH-1000 Lausanne 26, Switzerland ${ }^{1}$; \\ Institute of Medical Microbiology and Virology, Ruhruniversität, Bochum, ${ }^{2}$ and Institute \\ of Medical Microbiology, Infectious and Epidemic Diseases, Veterinary Faculty, \\ University of Munich, Munich, ${ }^{4}$ Germany; and Department of \\ Microbiology, Akita University School of \\ Medicine, Akita, Japan ${ }^{3}$
}

Received 31 January 1994/Returned for modification 12 April 1994/Accepted 15 August 1994

\begin{abstract}
Bovine rotavirus (BRV) V1005, like 34 further cell culture-adapted strains in a 6-year survey in Upper Bavaria, Germany, is not a P12 but a P5 P-type rotavirus. The conclusion is based on dot blot hybridization with P1-, P5-, and P11-specific cDNAs, encompassing the VP8* region of major sequence diversity, and on PCR using P1-, P5-, and P11-specific primer pairs derived from the VP5* region of VP4 (VP5* and VP8*, respectively, are the larger and smaller tryptic cleavage products of VP4). Sequencing of the hyperdivergent region of VP4 confirmed the close relatedness of BRV V1005 to BRV UK, the P5 prototype virus.
\end{abstract}

Group A bovine rotaviruses (BRVs) are a major infectious cause of diarrhea in calves. Both outer capsid rotaviral proteins, VP4 and VP7, can independently mediate active and passive immunity (5). The neutralization specificity carried on VP7 is referred to as the G serotype, and that carried on VP4 is referred to as the $P$ serotype. By the unified serotyping scheme (5), group A rotaviruses (RVs) are currently classified into at least $14 \mathrm{G}$ serotypes. RV $\mathrm{G}$ serotypes 6 and 10 predominate in cattle from Britain (17), Germany (2), Argentina (1), the United States (14), and Japan (19). At least 12 P types present among human and animal RV strains have been reported (18). On the basis of serological analysis, at least three $\mathrm{P}$ serotypes exist among $\mathrm{BRV}$ isolates $(10,18)$. A possible fourth P serotype, represented by BRV 678 (17) and BRV V1005 (3), has been identified serologically (18). BRV V1005 and about 80 further BRV strains were isolated into cell culture during a 6-year survey of calves with diarrhea from dairy farms around Munich, Germany $(2,3)$. We were surprised by the allocation of BRV V1005 to a new P12 serotype, as our previous peptide mapping (3) and partial sequencing of its VP4 (see below) indicated a close relatedness of V1005 to BRV UK. To settle this apparent contradiction, we determined the P types of BRV V1005 and of 34 further BRV isolates arbitrarily chosen from cell culture-adapted viruses in this Bavarian survey.

Serology. Routine $P$ serotyping of BRV remains problematic because hyperimmunization of laboratory animals with RV induces only a poor anti-VP4 antibody response. This was also demonstrated in our study. Guinea pig hyperimmune sera were raised against SA11 $\times$ NCDV reassortant N-4 having VP4 from NCDV and VP7 from SA11 (13) and DS-1 $\times$ UK reassortant RV having VP4 from UK and VP7 from DS-1 (11). High antibody titers were induced against the reassortant RV DS-1 $\times$ UK, but the antisera failed to recognize BRV UK. In contrast, one of two antisera raised against reassortant $\mathrm{N}-4$

\footnotetext{
* Corresponding author. Mailing address: Nestec Ltd., Nestlé Research Centre, P.O. Box 44, CH-1000 Lausanne 26, Switzerland. Phone: 4121785 8676. Fax: 4121785 8925. Electronic mail address: CABIAKMAN@CLIENTS.SWITCH.CH.
}

specifically recognized BRV NCDV. This antiserum was chosen to screen the German BRV isolates (Table 1); only four isolates were neutralized by antiserum dilutions of 300 to 600 , which are 5- to 10-fold lower than neutralization titers against P1 reference strain NCDV. We received from Snodgrass et al. (18) their rabbit antisera raised against reassortant RVs representing the different bovine $P$ serotypes. However, with the exception of the P1-specific antiserum, the neutralizing-antibody titers of these sera were too low to be of use in our neutralization assay. This observation demonstrated independently the difficulty of raising VP4-specific antisera with reassortant RV as antigen.

Dot blot hybridization. Nucleic acid probes and PCR are therefore more promising methods for $\mathbf{P}$ typing. A liquid hybridization method using single-stranded RNA from cloned BRV UK gene segment 4 demonstrated that BRV from Britain showed P types related to that of P5 BRV UK (16). Recently, dot blot hybridization assays for the typing of VP4 from BRV strains were described. cDNA probes were prepared from the hyperdivergent regions (nucleotides 211 to 686) of gene segment 4 (15). Dot blot assays revealed P1, P5, and P11 types in BRV field strains from North America, but $40 \%$ of the strains were untypeable (14). In our study, partiallength gene $4 \mathrm{cDNA}$ encompassing regions of major sequence diversity (nucleotides 200 to 700 ) was prepared by PCR amplification of gene segment 4 of BRV NCDV, UK, V1005, and B223 as described previously (2). Primer 1 consisted of bases 10 to 31 in the positive strand of gene 4 ( $5^{\prime}$ CCCGG GATCCATGGCTTCGCTCATTTATAGAC), and primer 2 (5'CCCGGGATCCCTTTCCACAATGAAGTCTTTGA) was derived from the complementary strand between bases 778 and 799 of gene 4 . Both primers contained sequences for creating a Bam HI restriction site at their $5^{\prime}$ end. The cDNAs corresponding to the hypervariable region of VP4 from the different BRV P types were cloned into the plasmid pUC19 and were partially sequenced in both directions by the dideoxy chain termination method by using the $\mathrm{T} 7$ polymerase sequencing system with the M13 universal primers. This confirmed their identity with sequences published for BRV NCDV and UK (references 6 and 9 and data not shown). 
TABLE 1. Characterization of reference BRV isolates and cell culture-adapted BRV isolates from a local survey conducted in Germany by using the neutralization test, dot blot hybridization, and PCR

\begin{tabular}{|c|c|c|c|c|c|c|}
\hline \multirow{2}{*}{ Isolate code/yr } & \multirow{2}{*}{ G type ${ }^{a}$} & \multirow{2}{*}{$\begin{array}{c}\text { Neutrali- } \\
\text { zation }^{\text {titer }}\end{array}$} & \multicolumn{4}{|c|}{$\begin{array}{l}\text { Dot blot hybridization }{ }^{c} \text { with } \\
\text { indicated cDNA probe }\end{array}$} \\
\hline & & & NCDV & UK & B223 & 1005 \\
\hline \multicolumn{7}{|l|}{ Controls } \\
\hline NCDV & 6 & 3,200 & + & - & - & - \\
\hline UK & 6 & $<100$ & - & + & - & + \\
\hline DS- $1 \times$ UK & 2 & $<100$ & - & + & - & + \\
\hline $\mathrm{N}-4$ & 3 & 12,800 & + & - & - & - \\
\hline
\end{tabular}

\section{Survey isolates}

$\begin{array}{llrlllll}\text { V1005 } & 10 & <100 & - & + & - & + & \text { P5 } \\ 627 / 77 & 6 & 100 & - & - & - & - & \text { P5 } \\ 666 / 77 & 6(?) & <100 & - & + & - & + & \\ 1429 / 77 & 6 & <100 & - & - & - & - & \text { P5 } \\ 10 / 78 & 10 & 400 & - & + & - & + & \\ 28 / 78 & ? & 200 & - & + & - & (+) & \\ 124 / 78 & 6 & <100 & - & (+) & - & (+) & \text { P5 } \\ 216 / 78 & 10 & <100 & - & (+) & - & - & \text { P5 } \\ 303 / 78 & 6 & 100 & - & + & - & + & \text { P5 } \\ 314 / 78 & 10 & <100 & - & + & - & + & \\ 601 / 78 & 6 & 100 & - & (+) & - & + & \\ 623 / 78 & 6 & <100 & - & + & - & + & \\ 675 / 78 & 6 & <100 & - & + & - & + & \\ 915 / 78 & 6 & 300 & - & + & - & + & \text { P5 } \\ 955 / 78 & 6 & <100 & - & + & - & + & \\ 1050 / 78 & 6 & <100 & - & (+) & - & (+) & \text { P5 } \\ 1150 / 78 & 6 & <100 & - & - & - & - & \text { P5 } \\ 1237 / 78 & 6 & <100 & - & + & - & (+) & \\ 1446 / 78 & 6 & <100 & - & + & - & + & \\ 470 / 79 & 10 & <100 & - & + & - & + & \\ 522 / 79 & 6 & <100 & - & (+) & - & - & \text { P5 } \\ 616 / 79 & 10 & 200 & - & + & - & + & \\ 638 / 79 & 10 & <100 & - & (+) & - & (+) & \text { P5 } \\ 718 / 79 & 10 & <100 & - & + & - & + & \\ 734 / 79 & 10 & <100 & - & + & - & (+) & \text { P5 } \\ 770 / 79 & 6 & <100 & - & + & - & (+) & \\ 437 / 80 & 6(?) & <100 & - & + & - & + & \text { P5 } \\ 474 / 80 & 10 & <100 & - & - & - & (+) & \text { P5 } \\ 479 / 80 & 10 & 600 & - & (+) & - & + & \\ 468 / 82 & 6 & <100 & - & + & - & + & \\ 125 / 83 & 6 & <100 & - & - & - & - & \text { P5 } \\ 274 / 83 & 6 & \text { NT } & - & + & - & + & \\ 595 / 83 & ? & <100 & - & (+) & - & + & \\ 709 / 83 & 6 & 600 & - & + & - & + & \end{array}$

${ }^{a}$ According to reference 2 .

${ }^{b}$ Neutralization with the P1-specific antiserum. Preimmune titers, $<50$. NT, not tested.

${ }^{c}-$, no hybridization; $(+)$, weak hybridization; + , strong hybridization with the indicated probe.

${ }^{d}$ Type determined by PCR as performed according to reference 8 . When no $P$ type is given, the isolate was not tested.

In dot blot hybridization assays, the NCDV-specific cDNA probe did not cross-hybridize with RNA from reference BRV strains (V1005, B223, and UK) or any of the BRV isolates from Germany (Fig. 1B). The DNA probe prepared from BRV B223 hybridized specifically with RNA from BRV B223 but with none of the reference BRV strains or the isolates from Germany (Fig. 1C). In contrast, cDNA prepared from VP4 of BRV UK hybridized with 29 of the 34 German BRV isolates (Fig. 1A). Notably, it hybridized also with RNA from BRV V1005 (Fig. 1D). In fact, all German BRV isolates which hybridized strongly with the UK-specific cDNA probe (Fig. 1A) also hybridized strongly with the V1005-specific cDNA probe (data not shown).
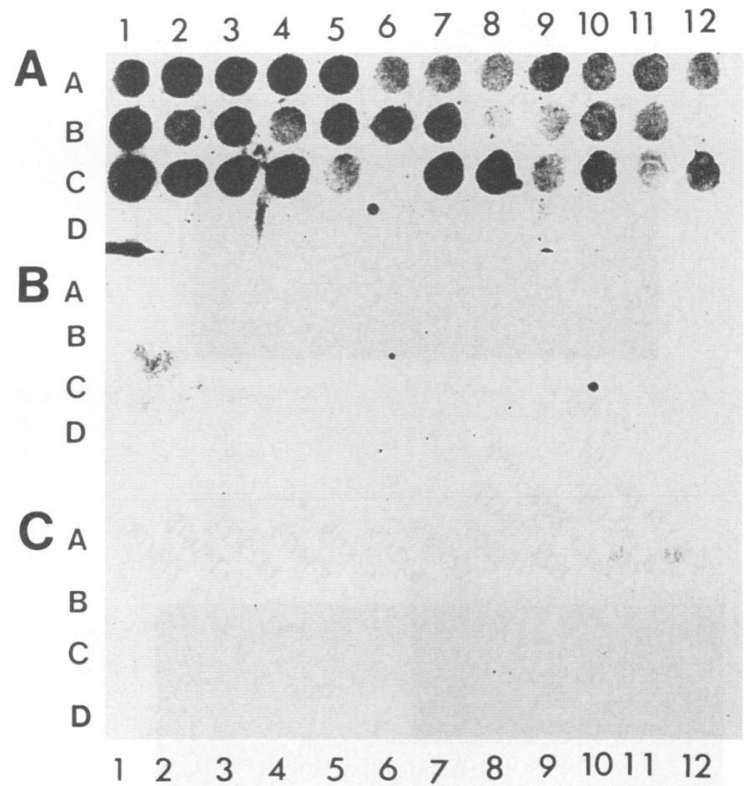

D
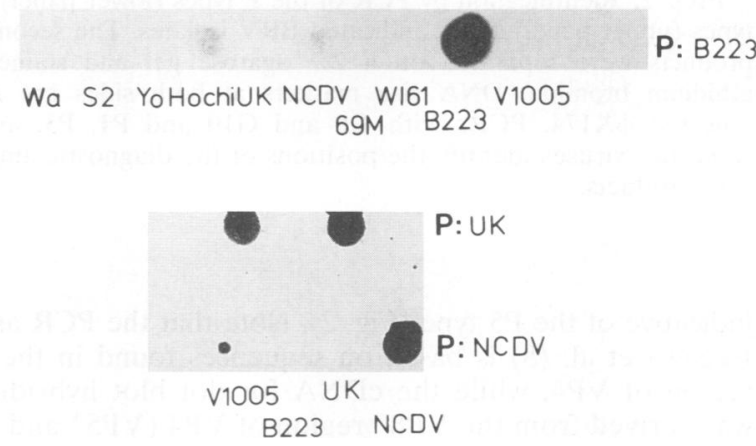

FIG. 1. Dot blot hybridization of the UK (A), NCDV (B), and B223 (C) gene 4 PCR probes under high-stringency conditions. The $\mathrm{RV}$ isolates in rows $\mathrm{A}$ to $\mathrm{D}$ and columns 1 to 12 are identified by their code number and year of isolation: $\mathrm{A} 1,955 / 78 ; \mathrm{A} 2,718 / 79 ; \mathrm{A} 3$, 1237/78; A4, 616/79; A5, 470/79; A6, 718/79; A7, 638/79; A8, 522/79; A9, 274/83; A10, 1334/78; A11, 437/80; A12, 595/83; B1, 915/78; B2, 734/79; B3, 28/78; B4, 479/80; B5, 303/78; B6, 770/79; B7, 10/78; B8, 474/80; B9, 216/78; B10, 124/78; B11, 601/78; B12, 627/77; C1, 709/83; C2, 1446/78; C3, 666/77; C4, 718/79; C5, 238/86; C6, 125/83; C7, 623/78; C8, 675/78; C9, 1050/78; C10, 314/78; C11, 1429/77; C12, 468/82; D1, 1150/78; D2, 993/83. (D) Control hybridization of the indicated cDNA probes $(\mathrm{P})$ against the indicated human and bovine reference viruses.

PCR. Comparative analysis of the genes determining $\mathbf{P}$ serotypes of BRVs allowed the development of PCR-based assays (8). PCR assays revealed P1, P5, and P11 types in cell culture-adapted BRV strains from a survey in Japan, with only $5 \%$ of the isolates being untypeable (19). The typing method comprised three steps: reverse transcription of BRV RNA; a first PCR amplification with common primers; and a second PCR amplification with P1-, P5-, and P11-specific or G6- and G10-specific primers as described previously (8). Similar selfconfirmatory heminested PCR typing assays have previously been used for both human and animal RVs and tested for field isolates. PCR was performed on BRV V1005 and a subgroup of Bavarian BRV isolates which could not be typed by dot blot hybridization (Table 1). All isolates yielded a 659-bp product 

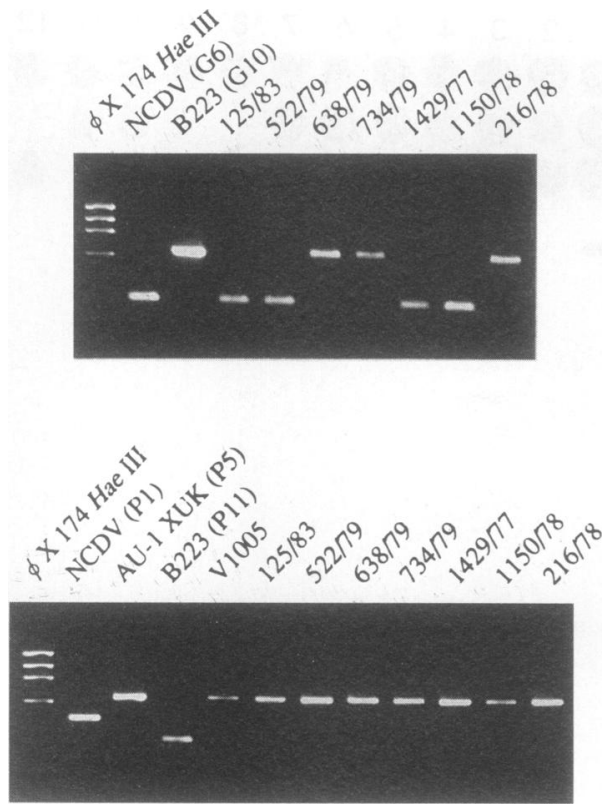

FIG. 2. Identification by PCR of the P types (lower panel) and G types (upper panel) of the indicated BRV isolates. The second PCR products were separated on a $2 \%$ agarose gel and stained with ethidium bromide. DNA size markers at both sides are HaeIIIdigested $\phi X 174$. PCRs with G6 and G10 and P1, P5, and P11 reference viruses identify the positions of the diagnostic amplification products.

indicative of the P5 type (Fig. 2). Note that the PCR assay of Isegawa et al. (8) is based on sequences found in the VP5* region of VP4, while the cDNA for dot blot hybridization was derived from the VP8* region of VP4 (VP5* and VP8*, respectively, are the larger and smaller tryptic cleavage products of VP4). G typing by PCR (8) confirmed the G type of these isolates determined previously by dot blot hybridization (compare Fig. 2 with Table 1).

Partial sequencing. To further characterize the relationship between VP4s of BRV UK and V1005, the sequence of the hyperdivergent region was determined for the V1005-specific cDNA probe. The sequence between nucleotides 10 and 799 showed 90 and $95 \%$ sequence identity with the published (9) homologous BRV UK sequence at the nucleotide and the amino acid levels, respectively (Fig. 3). Note that BRV B641, a further P5 BRV strain, also differs in this region from BRV UK by about $10 \%$ at the nucleotide level (7).

Snodgrass et al. (18) have proposed a new $\mathrm{P}$ type (P12) found in BRV isolates 678, WC3, and V1005. Despite a lack of serological data, the three DNA-based P-typing methods, however, unequivocally allocate V1005 to the P5 type.

In our survey of 34 German BRVs, 19 G6-P5 types (56\%) and 11 G10-P5 types (32\%) were identified, while 4 strains $(12 \%)$ showed the P5 type but were of doubtful G type. P5 was also the preponderant P type in BRVs from Japan (19), the United States (14), and Britain (16). No P1 or P11 types were detected in our survey. BRVs of the P1 type were found in 2 and $10 \%$ of Japanese and North American isolates, respectively $(14,19)$. P1 types are rare in Australia (7) and Britain (16). The currently available BRV vaccine strain (NCDV, G6-P1) might thus be unsuitable in many areas of the world. Cross-protection tests with calves implicated VP4 as an important antigen in the active immune response to $\mathrm{RV}$ infection in bovines (20). A G6-P5 combination may thus be a better vaccine candidate.

Our data do not represent a true epidemiological surveillance for a number of reasons. The survey was geographically limited to the area of Upper Bavaria around Munich, Germany. It was also limited in time to a 6-year period between 1977 and 1983. After introduction of dam vaccination with an inactivated V1005-based vaccine (4), BRV isolates were no longer collected. Note that the viruses investigated for their $\mathrm{P}$ type were cell culture-adapted BRV strains and not viruses in fecal samples (2). Since VP4 has been documented to be associated with viral growth (12), cell culture-adapted BRVs

$\mathrm{V} 1005$ MASLIYRQLL ANSYAVDLSD EIQSVGSEKN QRVTVNPGPF AQTGYAPVNW GPGEVNDSTV VQPVLDGPYQ PASFDLPVGN
UK (P5)
NCDV (P1)

81 WMLLAPTGPG VVVEGTDNSG RWLSVILIEP GVTSETRTYT MFGSSKQVLV SNVSVSKWKF VEMMKTAVDG DYAEWGTLLS

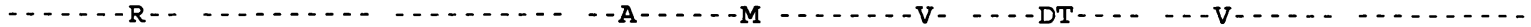

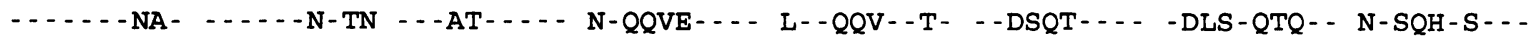

161 DTKLYGMKY GERLFIYEGE TPNATTKGYI VTNYASVEVR PYSDFYIISR SQESACTEYI NNGLPPIQNT RNVVPVAISS

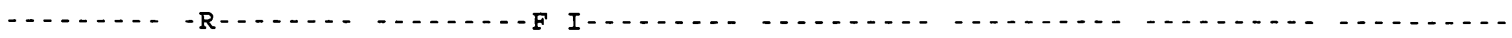

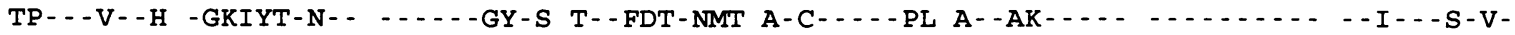

241 RSIKPREVQA NEDIVVSKTS LWK

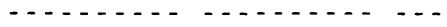
- N-VYTRA-P -Q- - - . - . - .

FIG. 3. Sequence alignment of the hyperdivergent region of VP4 (amino acid positions 1 to 263) from BRV V1005 with the published sequence (9) of P5 prototype BRV UK and the published sequence (6) of P1 prototype BRV NCDV. 
could be biased with respect to true field isolates. Note that a true field survey from Britain showed nearly exclusively P5 type BRV strains, as did our German survey (16).

Finally, we restate that a true $P$ serotype must be defined by a neutralizing antibody. DNA-based methods can be accepted as proxy measures only if sufficient data from surveys demonstrate the concordance of the two techniques. Lack of appropriate antibody has precluded up to now such an assessment.

We thank D. Snodgrass for rabbit hyperimmune sera, H. B. Greenberg and P. A. Offit for reassortant RVs, A. Maron for technical assistance in DNA sequencing, and D. Pridmore and A. Constable for reading the manuscript.

\section{REFERENCES}

1. Bellinzoni, R. C., J. O. Blackhall, N. M. Mattion, M. K. Estes, D. R. Snodgrass, J. L. La Torre, and E. A. Scodeller. 1989. Serological characterization of bovine rotaviruses isolated from dairy and beef herds in Argentina. J. Clin. Microbiol. 27:26192623.

2. Brüssow, H., W. Eichhorn, A. Rohwedder, D. Snodgrass, and J. Sidoti. 1991. Cattle develop neutralizing antibodies to rotavirus serotypes which could not be isolated from faeces of symptomatic calves. J. Gen. Virol. 72:1559-1567.

3. Brüssow, H., D. Snodgrass, T. Fitzgerald, W. Eichhorn, R. Gerhards, and A. Bruttin. 1990. Antigenic and biochemical characterization of bovine rotavirus V1005, a new member of rotavirus serotype 10. J. Gen. Virol. 71:2625-2630.

4. Eichhorn, W., P. A. Bachmann, G. Baljer, P. Plank, and P. Schneider. 1982. Vakzinierung hochträchtiger Rinder mit einem kombinierten Rotavirus/E. coli K99 Impfstoff zur Prophylaxe von Durchfallerkrankungen bei neugeborenen Kälbern. Tierärztl. Umsch. 37:599-604

5. Estes, M. K., and J. Cohen. 1989. Rotavirus gene structure and function. Microbiol. Rev. 53:410-449.

6. Hardy, M. E., G. N. Woode, Z. Xu, and M. Gorziglia. 1991. Comparative amino acid sequence analysis of VP4 for VP7 serotype 6 bovine rotavirus strains NCDV, B641, and UK. J. Virol. 65:5535-5538.

7. Huang, J. A., H. S. Nagesha, D. R. Snodgrass, and I. H. Holmes. 1992. Molecular and serological analyses of two bovine rotaviruses (B-11 and B-60) causing calf scours in Australia. J. Clin. Microbiol. 30:85-92.

8. Isegawa, Y., O. Nakagomi, T. Nakagomi, S. Ishida, S. Uesugi, and S. Ueda. 1993. Determination of bovine rotavirus $G$ and $P$ serotypes by polymerase chain reaction. Mol. Cell. Probes 7:277-284.
9. Kantharidis, P., M. L. Dyall-Smith, G. W. Tregar, and I. H. Holmes. 1988. Nucleotide sequence of UK bovine rotavirus segment 4: possible host restriction of VP3 genes. Virology 166:308315.

10. Matsuda, Y., O. Nakagomi, and P. A. Offit. 1990. Presence of three P types (VP4 serotypes) and two G types (VP7 serotypes) among bovine rotavirus strains. Arch. Virol. 115:199-207.

11. Midthun, K., H. B. Greenberg, Y. Hoshino, A. Z. Kapikian, R. G. Wyatt, and R. M. Chanock. 1985. Reassortant rotaviruses as potential live rotavirus vaccine candidates. J. Virol. 53:949-954.

12. Offit, P. A., G. Blavat, H. R. Greenberg, and H. F. Clark. 1986 Molecular basis of rotavirus virulence: role of gene segment 4. J. Virol. 57:46-49.

13. Offit, P. A., H. F. Clark, G. Blavat, and H. B. Greenberg. 1986 Reassortant rotaviruses containing structural proteins VP3 and VP7 from different parents induce antibodies protective against each parental serotype. J. Virol. 60:491-496.

14. Parwani, A. V., H. A. Hussein, B. I. Rosen, A. Lucchelli, L. Navarro, and L. J. Saif. 1993. Characterization of field strains of group $\mathrm{A}$ bovine rotaviruses by using polymerase chain reactiongenerated $\mathrm{G}$ and $\mathrm{P}$ type-specific cDNA probes. J. Clin. Microbiol. 31:2010-2015.

15. Parwani, A. V., B. I. Rosen, M. A. McCrae, and L. G. Saif. 1992 Development of cDNA probes for typing group A bovine rotaviruses on the basis of VP4 specificity. J. Clin. Microbiol. 30:27172721.

16. Redmond, D. L., N. F. Inglis, T. A. Fitzgerald, D. R. Snodgrass, and A. G. Herring. 1992. A liquid-hybridization method for typing the VP4 and VP7 genes of bovine rotaviruses. J. Virol. Methods 39:165-177.

17. Snodgrass, D. R., T. Fitzgerald, I. Campbell, F. M. M. Scott, G. F. Browning, D. L. Miller, A. J. Herring, and H. B. Greenberg. 1990. Rotavirus serotypes 6 and 10 predominate in cattle. J. Clin. Microbiol. 28:504-507.

18. Snodgrass, D. R., Y. Hoshino, T. A. Fitzgerald, M. Smith, G. F. Browning, and M. Gorziglia. 1992. Identification of four VP4 serological types ( $\mathrm{P}$ serotypes) of bovine rotavirus using viral reassortants. J. Gen. Virol. 73:2319-2325.

19. Suzuki, Y., T. Sanetaka, M. Sato, K. Tajima, Y. Matsuda, and O. Nakagomi. 1993. Relative frequencies of G (VP7) and P (VP4) serotypes determined by polymerase chain reaction assays among Japanese bovine rotaviruses isolated in cell culture. J. Clin. Microbiol. 31:3046-3049.

20. Woode, G. N., N. E. Kelso, T. F. Simpson, S. K. Gaul, L. E. Evans, and L. Barbiuk. 1983. Antigenic relationships among some bovine rotaviruses: serum neutralization and cross-protection in gnotobiotic calves. J. Clin. Microbiol. 18:358-364. 